\title{
Potential for ultrasound in occult submucous cleft palate?
}

\author{
Zachary Cole-Healy
}

Received: 3 July 2012 / Revised: 11 July 2012 / Accepted: 17 July 2012 / Published online: 31 August 2012

(C) Springer-Verlag 2012

Sir,

Submucous cleft palate is rarer than overt cleft palate. While it is a condition with similar anatomical and functional basis as overt cleft palate, unlike overt cleft palate the diagnosis of submucous cleft palate is somewhat troublesome. Traditionally, the diagnosis of submucous cleft palate has relied on the coincidence of a bifid uvula, notching of posterior border of the hard palate and a midline diastasis of the palatal muscles, which is known as Calnan's triad [1]. However, there is a group of children who do not satisfy these three criteria, but develop the consequence of submucous cleft palate, velopharyngeal incompetence. They are classed as having an occult submucous cleft palate and account for $50 \%$ of children with submucous cleft palate [2]. The signs of velopharyngeal incompetence are eustachian tube dysfunction, conductive hearing loss and hypernasal speech. These signs take time to develop, causing a delay in occult submucous cleft palate diagnosis, which affects treatment outcomes with increased rates of reoperation [3].

There is a high prevalence of submucous cleft palate in children with isolated cleft lip, and $12 \%$ of children with isolated cleft lip also have a classic submucous cleft palate, while $24 \%$ have an occult submucous cleft palate [4]. The isolated cleft lip population therefore provides a population suitable for occult submucous cleft palate screening. A tool that could identify children with occult submucous cleft palate from the isolated cleft lip population would improve care.

Z. Cole-Healy $(\square)$

The Medical School, University of Sheffield,

Beech Hill Road,

Sheffield, South Yorkshire S10 2RX, UK

e-mail:mda07zc@sheffield.ac.uk
Very limited research has been done on the application of ultrasound to evaluate the palate postnatally. However, technological advancement of endoscopic US technology has made it integral during the assessment of loco-regional cancers of the gastrointestinal tract. Endoscopic US could be used to visualise and evaluate the musculature of the soft palate to identify submucous cleft palate. Indeed, the MTurbo ${ }^{\circledR}$ US system (Sonosite Inc., Bothell, WA, USA) has been used to evaluate the palate of three children with submucous cleft palate, thus identifying the absence of the central uvularis muscle and discontinuation of the levator sling in each of the submucous cleft palate cases, findings that were confirmed during palatoplasty [5].

Calnan's triad is more than half a century old and provides a sensitivity of only $50 \%$, yet it remains the mainstay of submucous cleft palate diagnosis. Research into using US to identify children at risk of submucous cleft palate could make detection of occult submucous cleft palate possible earlier. The question of whether endoscopic US could succeed in this task is one that should be explored.

\section{References}

1. Calnan J (1954) Submucous cleft palate. Br J Plast Surg 6:264

2. Kaplan EN (1975) The occult submucous cleft palate. Cleft Palate J $12: 356$

3. Pensler J, Bauer B (1988) Levator repositioning and palatal lengthening for submucous clefts. Plast Reconstr Surg 82:765-9

4. Gosain AK, Conley SF, Santoro TD et al (1999) A prospective evaluation of the prevalence of submucous cleft palate in patients with isolated cleft lip versus controls. Plast Reconstr Surg 103:1857-1863

5. Meier J, Banks C, White D (2011) Ultrasound imaging to identify occult submucous cleft palate. Otolaryngoly Head Neck Surg $145: 249-250$ 